\title{
ARTICULAÇÕES FEDERATIVAS EM CONTEXTOS METROPOLITANOS
}

Carlos Eduardo Nobre ${ }^{1}$

Resumo: Discutimos as articulações federativas verticais e horizontais em contextos metropolitanos, partindo da problemática do "lugar" da metrópole frente ao sistema federativo brasileiro. Se, por um lado, municípios que integram regiões metropolitanas se articulam verticalmente com governos estaduais e Federal; por outro lado, estes mesmos municípios se desarticulam horizontalmente. $O$ resultado seria a fragmentação e desintegração da metrópole. Advogamos a necessidade de uma solidariedade institucional a partir das dinâmicas internas à metrópole, ao tempo em que propomos repensar outra configuração federativa para enfrentamento dos problemas metropolitanos.

Palavras-chave: Federação. Articulações intergovernamentais. Planejamento e Gestão Metropolitanos. Brasil.

\section{FEDERATIVE ARTICULATIONS IN METROPOLITAN CONTEXTS}

Abstract: We discuss vertical and horizontal federative articulations in metropolitan contexts, based in the problematic of the "place" of the metropolis in the framework of the federative system. If, on one hand, municipalities that integrate metropolitan regions articulate themselves vertically with states and Federal governments; on the other hand, these same municipalities disarticulate horizontally. The result would be the fragmentation and disintegration of the metropolis. We propose the need of an institutional solidarity based on the internal dynamics of the metropolis, while at the same time we propose to rethink another federative configuration to confront metropolitan problems.

Keywords: Federation. Intergovernmental Relations. Metropolitan Planning and Management. Brazil.

\section{ARTICULACIONES FEDERALES EN CONTEXTOS METROPOLITANOS}

Resumen: Discutimos las articulaciones federales verticales y horizontales en contextos metropolitanos, basado en la problemática del "lugar" de la metrópoli frente al sistema federal brasileño. Si, por un lado, los municipios que integran regiones metropolitanas se articulan verticalmente con los estados miembros de la federación e con la Unión; por otro lado, estos mismos municipios se desarticulan horizontalmente. El resultado sería la fragmentación y desintegración de la metrópoli. Abogamos por la necesidad de una solidaridad institucional a partir de las dinámicas internas a la metrópoli, al tiempo que proponemos repensar otra configuración federal para enfrentar los problemas metropolitanos.

Palabras clave: Federación. Articulaciones intergubernamentales. Planificación y Gestión Metropolitana. Brasil.

\footnotetext{
${ }^{1}$ Universidade Estadual do Maranhão, Departamento de História e Geografia, São Luís, Brasil, cdnobre19@gmail.com, https://orcid.org/0000-0003-1461-8058
} 


\section{Introdução}

O debate sobre as regiões metropolitanas (RM) em contextos federativos requer, cada vez mais, a busca pela compreensão do fenômeno metropolitano ou, como sugerido por Ribeiro (2013a; 2013b), desse fato metropolitano que nos aparece como enigma. Trata-se de um fenômeno geográfico que é ao mesmo tempo um fenômeno técnico-social, econômico, cultural e político. Para Santos (2005 [1993], p. 88), "o fato metropolitano se apresenta como uma totalidade menor dentro da totalidade maior, constituída pela formação social nacional”.

Propomos uma reflexão em torno do fenômeno metropolitano brasileiro levando em conta a organização política do território nacional por um sistema federativo. Refletimos, em termos gerais, os impasses e as contradições entre a metrópole existente como fato (RIBEIRO, 2013a) e a metrópole instituída a partir de uma divisão político-administrativa para o planejamento e gestão do território.

Se, por um lado, a metrópole como fato é integrada do ponto de vista das dinâmicas sociais e territoriais; por outro lado, a sua instituição como região políticoadministrativa atrita com a compartimentalização política do território pela federação, tendo em vista a instituição dos municípios como entes federados autônomos. Assim, o conjunto de municípios que integram uma região metropolitana acabaria por fragmentá-la do ponto de vista do planejamento e da gestão.

No Brasil, as regiões metropolitanas constituem uma forma jurídica cuja divisão político-administrativa se sobrepõe às divisões político-administrativas municipais gerando - não raro - tensões e conflitos de difíceis resoluções, sobretudo, no campo das políticas públicas. Outro problema é que a vida de relações na metrópole nem sempre corresponderia ou coincidiria com sua forma jurídica, isto é, político-administrativa.

As regiões metropolitanas, nesse sentido, admitem uma divisão políticoadministrativa, porém, sem serem reconhecidas como um ente da federação, não admitem autonomia política, administrativa e fiscal, como nos casos dos estados e municípios.

Tendo em vista essa problemática mais geral, discutimos, teoricamente, sobre os limites e as possibilidades para efetivação de articulações federativas horizontais que envolvam os municípios que integram regiões metropolitanas no sentido da implementação de políticas públicas que enfrentem os problemas e as questões sociais compartilhadas pelos entes que conformam essas regiões. 
Para tanto, buscamos sistematizar e discutir, a partir da literatura especializada, algumas razões ou fatores que explicitariam os constrangimentos para a efetivação de uma cooperação intergovernamental horizontal no sentido de empreendimento de políticas públicas intermunicipais que levem em conta a totalidade da região.

A discussão está estruturada da seguinte forma: Inicialmente, tecemos breves considerações acerca do fato metropolitano e de suas recentes transformações morfológicas, funcionais e estruturais derivadas das reestruturações produtivas que marcam o período atual e que imputam desafios, por um lado, às configurações territoriais concernentes à engenharia federativa e, por outro lado, ao planejamento e gestão dos espaços metropolitanos encaixados nesse sistema federativo.

Em seguida, discorremos, a partir de Castillo et al. (1997), sobre a necessária solidariedade institucional concatenada com uma solidariedade territorial que permita o empreendimento de articulações federativas horizontais entre os municípios que integram regiões metropolitanas. Trata-se de refletir o fenômeno metropolitano na encruzilhada das tensões federativas no sentido de pensar uma federação de lugares, como proposta por Milton Santos (2010), levando em conta as demandas sociais presentes na metrópole.

Por fim, discutimos os limites e possibilidades às articulações federativas horizontais em contextos metropolitanos, bem como alguns fatores de constrangimento ao empreendimento de tais articulações tendo em vista distintos argumentos apresentados pela literatura que se debruça sobre a questão.

Dentre os desafios que se apresentam, está o de fazer coincidir a metrópole como fato (RIBEIRO, 2013a, 2013b) e a sua correlata circunscrição territorial que permita a existência de um sistema organizacional e institucional que responda pela adequada gestão e administração da vida de relações a partir do interior da própria metrópole. Esse sistema se faz imprescindível, sobretudo, no âmbito das políticas públicas urbanas.

\section{Breves considerações acerca do fato metropolitano}

$\mathrm{Na}$ literatura, encontramos o tratamento da metrópole numa perspectiva da economia política do território, como fenômeno geográfico, na qual se inscreve a sua subdivisão no campo do conhecimento como um fenômeno regional. Também, lidase como fenômeno político, do qual emergem suas derivações no campo político- 
institucional e a sua face operacional, isto é, a metrópole como região ou unidade territorial de planejamento e gestão.

Ribeiro (2013b, p. 207) ressalta "o caráter historicamente móvel do conceito de metrópole, ou seja, a sua nova face pressupõe, teoricamente, a existência de determinados processos econômicos, institucionais e políticos". Para esta Socióloga, "a admissão da importância destes processos impede a generalização do conceito de metrópole a partir de critérios exclusivamente político-administrativos ou tradicionalmente funcionais" (ibid.). Essa assertiva já nos impõe desafios de monta para se pensar a metrópole em um contexto federativo, já que pensar a federação é pensar, também, em limites político-administrativos, jurisdicionais.

Entendemos a metrópole como um fenômeno que resulta do processo de urbanização e ao mesmo tempo condiciona esse processo. Por se tratar de um processo histórico, podemos considera-lo como um processo de metropolização. Para Di Méo (2008, p. 3) "[...] o termo "metropolização" faz referência a processos. Ele caracteriza tanto as formas quanto as funções e as dinâmicas dos maiores agrupamentos humanos de nosso tempo".

Para Lencioni (2015, p. 7), "o momento atual expressa [...] uma nova fase da história da urbanização na qual emerge com força o processo de metropolização do espaço [...]". Para esta autora, "é como se a metropolização do espaço se constituísse em uma segunda natureza da urbanização, no sentido de uma urbanização com nova essência e substância" (ibid.).

Santos (2012 [1994], p. 77) também afirma que o processo de urbanização de fato vem acompanhado do processo de metropolização como resultado do movimento contemporâneo do processo de mundialização. Mas enfatiza o fato dessa metropolização resultar de uma modernização que "é, ao mesmo tempo, seletiva e não igualitária, privilegiando uma parcela da população com o desenvolvimento simultâneo de novas classes médias e de um multidão de gente pobre" (ibid.).

Numa perspectiva da economia política do território, há um consenso estabelecido em torno dos processos contraditórios gerados pelo fenômeno da metropolização que consistiriam na combinação de forças de integração e dispersão ou forças fragmentadoras, tanto do ponto de vista social como territorial.

Santos (2009 [1990], p. 128), ao tratar dos fatores do crescimento metropolitano, diz que este "resulta de um conjunto de processos sistematicamente interligados, entre os quais a integração do território, a desarticulação das 
economias tradicionais [...]", paralelamente "ao processo de concentração das rendas" acompanhado da "baixa do rendimento médio e da expansão do número de empregos mal remunerados", levando o autor a definir essas contradições como "involução metropolitana" (SANTOS, 2012 [1994], p. 92)

Numa perspectiva morfológica, funcional e estrutural, De Mattos (2002, p. 21), ao tratar das metrópoles latino-americanas, afirma que se produz uma reestruturação territorial onde integração e dispersão formam parte de um mesmo processo:

[...] por un lado, una creciente integración y vinculación entre territorios cada vez más extensos, articulados por todo tipo de flujos, tanto materiales como inmateriales. Por otro, una dispersión de las actividades y la población, que favorece la formación de sub-centros en nodos periféricos de alta accesibilidad [...].

Ribeiro (2013b, p. 211) considera que a concentração de investimentos, equipamentos e recursos ao tempo em que se produz segregação socioespacial "constituem, talvez, os termos básicos do [...] equacionamento factual e teórico" da atual "estrutura interna da metrópole", tendo na "ação política e ideológica superestrutural do planejamento" a adequada produção da "infraestrutura (meios de consumo coletivos)" necessária ao atendimento dos "novos objetivos históricos a serem cumpridos pela aglomeração humana [...]: a agilização de fluxos financeiros e a apropriação privada do trabalho social acumulado no chão produzido nas metrópoles".

O que essas definições têm em comum é o fato da metrópole ser a um só tempo resultado de um processo de integração técnico-social que, nos dias atuais, se presta à estruturação e ao funcionamento dos circuitos superiores da economia urbana (Santos, 2004 [1979]) ao tempo em que conduz à fragmentação social e territorial. Esses processos contraditórios entre integração e fragmentação corresponderiam a uma nova morfologia espacial, ou melhor, a uma nova formaconteúdo.

Trata-se, segundo De Mattos (2006, p. 61), do fim da cidade autocentrada e compacta que passa a ser estruturada como "entrecruzamento de múltiplas redes, novos padrões de urbanização, trama contínua de assentamentos ao redor de um grande número de focos nodais em uma vasta região multifacetada".

Daí Lencioni (2015, p. 11) falar de uma urbanização regional ou da formação de uma megarregião caracterizada pela "integração produtiva e [pela] forte interação com a economia global e grande densidade de movimentos pendulares". O que 
Lencioni (ibid.) chama de megarregião ou urbanização regional, De Mattos (ibid.) chama de macrorregião metropolitana. Tratar-se-ia do mesmo processo fenomênico.

\section{Transformações recentes do fato metropolitano}

Por se tratar de um processo histórico, o fenômeno metropolitano pode ser situado no tempo-espaço a partir de um eixo sucessivo de eventos que configurariam as respectivas formas espaciais. Poderíamos definir, então, em linhas gerais, etapas ou momentos da formação do fato metropolitano.

Uma primeira etapa ou momento refere-se aquele que dá origem ao fenômeno da metrópole a partir de um tipo ou forma espacial urbana que seria a cidade autocentrada, compacta, típica do período industrial (DE MATTOS, 2006, p. 61) ou do período técnico-científico, como denomina Santos (2008 [1996]), e que finda na década de 1970. Os limites que demarcavam o sistema metropolitano eram mais bem definidos, inclusive por meio da paisagem onde se distinguia o meio ambiente urbano (adensado por construções) daquele meio ambiente rural (adensado por vegetações e atividades agrícolas).

O segundo momento, iniciado, se considerarmos o tempo externo do mundo, com a reestruturação produtiva pós-fordista ou pós-industrial (DE MATTOS, 2002), ou pela difusão do meio técnico-científico e informacional (SANTOS, 2008 [1996]), produziu um tipo de cidade dispersa com a construção dos grandes eixos rodoviários, dando início ao processo de integração regional dos municípios próximos ao município núcleo da metrópole. Esse seria o fenômeno metropolitano propriamente dito.

O terceiro momento é o atual, em que há uma radicalização do processo anterior, marcado pela "acentuação da metropolização expandida, de uma dilatação continuada de um periurbano difuso, de baixa densidade, de estrutura policêntrica, que prolonga a cidade em direções possíveis" (DE MATTOS, op. cit., p. 14), "aglutinando pequenas e médias cidades localizadas nos eixos de ligação entre as metrópoles" (ibid., p. 48).

Os limites anteriormente bem definidos pela própria paisagem em que se distinguiam mais ou menos facilmente o meio rural do meio urbano já não mais existem em uma região metropolitana como a de São Paulo, por exemplo. 
Todavia, no caso brasileiro, os limites municipais persistem, como cristalizações do passado, a despeito do espaço construído na metrópole dificilmente reconhecê-los.

Se, por um lado, as materialidades urbanas ou o espaço construído, com suas redes técnicas e conjunto de fixos e fluxos avançam e atravessam os limites da cidade (os limites periurbanos) e mesmo os limites municipais, por outro lado, estes últimos permanecem como limites. O que conforma a região metropolitana não é simplesmente um conjunto de municípios agregados e justapostos atravessados por redes técnicas e fluxos. É sobretudo a sua complexa vida de relações propiciadas pelos complexos sistemas de objetos e de ações (SANTOS, 2008 [1996]) instituídos pelas e instituidores das mais diversas divisões territoriais do trabalho.

Aqui destacamos a correlação entre o fenômeno metropolitano e o fenômeno regional que ganha novas dimensões e exigem uma reflexão em torno dos atuais limites político-administrativos municipais que compartimentalizam e fragmentam um território metropolitano que possui uma unidade e integridade regional. Como pensar e implementar políticas públicas em um contexto metropolitano e quais as consequências dessas implementações se não se considera o fato metropolitano em sua totalidade?

\section{Entre verticalidades e horizontalidades: a necessária solidariedade institucional metropolitana}

Ao reconhecer o fenômeno metropolitano como um fenômeno regional, é preciso nos debruçarmos, também, sobre a noção atualizada de região. De acordo com Santos (2008 [1996], p. 285), não é mais possível caracterizar a região somente pela solidariedade orgânica "que era o próprio cerne do fenômeno regional", pois hoje as regiões existem "porque sobre elas se impõem arranjos organizacionais, criadores de uma coesão organizacional baseada em racionalidade de origens distantes, mas que se tornam um dos fundamentos da sua existência e definição" (ibid.; loc. cit.).

Santos (ibid.) retoma de Durkheim (1999) a noção de solidariedade orgânica (ou mecânica) e de solidariedade organizacional para propor que um subespaço, região ou lugar possam ser definidos a partir desses dois tipos de solidariedades. A partir dessa noção, Santos (ibid., p. 166) sugere que o acontecer solidário se apresenta sob três formas no território: 1) sob a forma de um acontecer homólogo; 
2) sob a forma de um acontecer complementar e; 3) sob a forma de um acontecer hierárquico.

Os dois primeiros aconteceres pressupõem continuidade e contiguidade espacial (ibid.; CASTILLO et al.,1997, p. 78), proximidade física onde impera uma razão local que rege e é regida pela solidariedade orgânica fundamentada na própria lógica interna ao agrupamento e ao lugar. Esse princípio de acontecer era o cerne da tradicional noção e existência mesmo da região onde prevaleciam as horizontalidades. Esse princípio ainda fundamenta a noção e existência da região, todavia, a ele se combina o acontecer hierárquico que pressupõe descontinuidade, tele ação, imposição de interesses e lógicas exógenas onde prevalecem as verticalidades e cujo fundamento é a solidariedade organizacional (SANTOS, 2008 [1996]; ibid.).

Nesse sentido, a região, sobretudo, a região metropolitana, é conformada por esses três aconteceres onde predominam as duas solidariedades: orgânica e organizacional, conformando tanto um espaço contíguo com predomínio das horizontalidades e, ao mesmo tempo, interconectado com outros lugares onde predominam as verticalidades.

Mas Castillo et al. (1997) propõem ainda uma terceira solidariedade que seria responsável pela conformação e coesão dos subespaços: a solidariedade institucional. Segundo os autores, a solidariedade institucional "encontra suas bases numa coesão sócio-territorial dada pelo ordenamento jurídico e políticoadministrativo que tem vigência sobre um território circunscrito politicamente e que condiciona também a implantação e o arranjo de fixos e a distribuição de fluxos [...] no território" (ibid., p. 70)².

No caso de um território que é organizado politicamente por um sistema federativo, essa solidariedade institucional diz respeito, por um lado, à própria coesão interna dos entes federados por meio de sua administração (poder executivo e legislativo) e de sua arrecadação (impostos) (ibid., p. 79-80), bem como às articulações intergovernamentais que podem ser tecidas horizontalmente, ou seja, entre os próprios municípios de uma região metropolitana; ou verticalmente, entre municípios, estados e/ou União.

\footnotetext{
2 Para Castillo et al., a solidariedade institucional tratar-se-ia de um terceiro nível de regulação na determinação do lugar. Os autores definem a solidariedade institucional como aquela que responde pelas "ações políticas de governos nas escalas do município, do Estado federado, do Estado-Nação" tendo, portanto, "um papel na divisão territorial do trabalho, através das várias modalidades e escalas do Estado" (ibid. p. 79).
} 
A noção de solidariedade institucional se presta ao entendimento dos processos que conformariam duas situações contraditórias e ao mesmo tempo complementares do ponto de vista da coesão interna não só aos municípios tomados separadamente, mas à própria região metropolitana no que se refere à implementação de políticas públicas: 1) situações de integração político-institucional a partir das articulações federativas e intergovernamentais verticais e horizontais; 2) ou o seu inverso, isto é, situações de fragmentação político-institucional e, portanto, desarticulações com desdobramentos na execução das políticas públicas.

Desse modo, a partir de situações variadas, poder-se-ia tanto dirimir e enfrentar as desigualdades e injustiças territoriais como as amplificar, se levarmos em conta essa dialética interna e externa à metrópole.

\section{A metrópole na encruzilhada das tensões federativas}

Aqui chegamos a mais uma dimensão do fenômeno metropolitano, compreendido a partir do fenômeno regional: a sua dimensão político-institucional e a sua face operacional: a região metropolitana como unidade territorial de planejamento e gestão que se presta a uma dada racionalização da ação ou a uma ação racional do Estado em torno da problemática das políticas públicas.

Santos (2005 [1993]) já ressaltou as regiões metropolitanas como "regiões de planejamento, onde, todavia, o que é feito não atende a problemática geral da área, limitando-se a aspectos setoriais".

Esse fato teria a ver com o "lugar" reservado à região metropolitana no pacto federativo brasileiro. Enquanto municípios, estados e o próprio território nacional são circunscritos por fronteiras políticas que delimitam e condicionam a ação do Estado, as regiões metropolitanas são objetos de delimitações "fracas" do ponto de vista de uma necessária solidariedade institucional horizontal, e isso afetaria a articulação das ações necessárias ao enfrentamento dos problemas de interesse comum compartilhados pela região.

Enquanto os limites político-administrativos das regiões metropolitanas seriam "fracos", os limites político-administrativos dos municípios seriam "fortes" o bastante para constranger tais articulações. E isso teria a ver com os pactos para distribuição territorial do poder político assumidos na Constituição Federal de 1988.

Para compreender melhor esse argumento, vale a distinção da natureza dos limites inscritos no território para delimitação de um campo de forças ou de poder, 
como proposta por Cataia (2001). Primeiramente, a delimitação de territórios pelo Estado pressupõe a institucionalização de limites reconhecidos juridicamente e socialmente. Esses limites são representados por linhas "imaginárias", mas existentes concretamente por meio das normas.

Cataia (ibid., p. 44, 124-125) propõe uma distinção entre as linhas que delimitam fronteiras e todas as demais linhas que delimitam outras circunscrições e outros campos de ações. A distinção residiria no fato de que as linhas que demarcam fronteiras, ou melhor, circunscrevem um território por meio de fronteiras, correspondem ao exercício de um poder auto regulador (como no caso do território nacional de um Estado-nação, ou de um ente federado como os estados e, no caso da federação brasileira, também os municípios); enquanto que as demais linhas demarcariam uma circunscrição que é regulada de fora, que não se auto regula, como é o caso das regiões metropolitanas no Brasil que, desde a Constituição Federal de 1988, são reguladas pelos governos estaduais.

Mediante o fato dos limites político-administrativos das regiões metropolitanas não constituírem fronteiras internas, não poderiam se autorregular, formular, financiar e implementar suas políticas públicas. Desse modo, cada município dependeria muito mais das imposições externas e da capacidade de tecer articulações com níveis hierárquicos de poder, do que tecer conjuntamente os destinos da região ${ }^{3}$.

Em outros termos, as regiões metropolitanas resultariam muito mais de uma solidariedade organizacional e institucional hierárquica, imposta de fora, do que de uma solidariedade orgânica e institucional homóloga e complementar, imposta a partir de dentro, dos próprios municípios que a compõem, apesar de todas essas solidariedades coexistirem efetivamente ou potencialmente no mesmo espaço em tensão.

Castillo et al. (1997, p. 79-80) já haviam reconhecido esse fato quando afirmaram que "a coesão [político-institucional] existente dentro dos limites de cada município, por exemplo, por meio de sua administração [...], impõe a uma região metropolitana constrangimentos na esfera do planejamento territorial, se esta não possui um governo próprio que abranja todos os municípios que a constituem”.

\footnotetext{
${ }^{3}$ Para Cataia (ibid.), no Brasil, as fronteiras envelopam municípios e estados, o que ele considera como fronteiras internas que se distinguem das fronteiras que delimitam o território nacional ou 0 Estado-nação que seriam aquelas que resguardariam o território em relação a um exterior.
} 
O problema é que, nos moldes da atual Constituição Federal de 1988, ainda não é possível a existência de um governo metropolitano, sendo essa uma discussão que vem tomando espaço tanto na academia como entre as próprias instâncias dos poderes constituídos.

$\mathrm{Na}$ verdade, a ideia da metrópole como um quarto nível de poder constituído na federação brasileira "foi discutida na década de 1970, não tendo prosperado naquela ocasião porque enfraqueceria [...] o poder dos estados", segundo entrevistados da Empresa Paulista de Planejamento Metropolitano (Emplasa) (MOTTA e MIRANDA, 2013, p. 223).

Alguns autores que se debruçam sobre os estudos em torno das regiões metropolitanas admitem a necessidade de pensa-las como um quarto nível de poder na federação, com governos próprios, compostas por um conjunto de municípios, porém localizado, no sistema federativo, entre os municípios e o estado.

Saboia (1998, p. 232) menciona aqueles que falam de um "Federalismo das Regiões", também constituído como um quarto nível de poder, ao lado dos demais entes da federação: União, estados-membros, municípios e Distrito Federal.

$\mathrm{O}$ argumento para justificar as regiões metropolitanas como um quarto nível de poder também é defendido por Clementino $(2016$, p. 5) quando afirma que "a inexistência de um sistema de governo metropolitano é uma questão que dificulta a resolução dos problemas urbanos das maiores cidades do mundo", de modo que, no caso do Brasil, "a correção do distorcido pacto federativo brasileiro [teria] necessariamente de passar pelo devido reconhecimento da natureza e identidade das áreas metropolitanas [...]" (ibid., p. 9).

Abrucio e Franzese (2007) também apontam na mesma direção quando afirmam que um dos desafios colocados pela Federação à gestão pública brasileira diz respeito a:

Repensar os marcos políticos territoriais do país, reformulando as formas de governança regional. Em destaque, deve-se reformar a governança metropolitana e a macrorregional, que estão em crise desde o final da década de 1980. Atuar nesse front significa desmistificar a ideologia municipalista, segundo a qual os municípios devem ser a unidade básica da provisão e planejamento dos serviços públicos" (ibid., p. 17).

Mas talvez seja o argumento de Castillo et al. (1997) que mais nos interessaria como justificativa factível para se pensar as regiões metropolitanas no quadro federativo, a partir da noção de solidariedade institucional mediante o 
potencial e significado que tal noção carrega se formos considerar uma outra prática do Estado para resolução dos problemas sociais das metrópoles.

Castillo et al. (ibid., p. 80) partem do pressuposto de que, se correta a hipótese de que a solidariedade orgânica resulta de interações locais "[...] lançando bases para uma resistência a interesses remotos que ali tomam lugar"; e de que a solidariedade organizacional vincula-se mais diretamente a "interesses [...] mais distanciados [...] das demandas locais e regionais", a solidariedade institucional serviria "como um fiel da balança que ora aproxima-se mais e soma esforços com a solidariedade orgânica, ora tende a reforçar os vetores oriundos dos interesses globais, sustentando a solidariedade organizacional".

É nesse sentido que poderíamos buscar uma saída para os problemas ditos metropolitanos: a partir do alargamento e aprofundamento das solidariedades institucionais e organizacionais, mas, sobretudo, que fossem capazes de se basearem nas solidariedades orgânicas já presentes na própria metrópole, isto é, a partir das dinâmicas preexistentes e vinculadas à vida de relações do lugar.

\section{Limites e possibilidades de articulações federativas em contextos metropolitanos}

A partir do quadro atual do sistema federativo brasileiro, e, levando-se em conta o status das regiões metropolitanas enquanto recortes político-administrativos distintos daqueles que são reconhecidos como entes da federação (com autonomia política, administrativa e fiscal), apontamos três possibilidades - potenciais ou efetivas - de articulações federativas em contextos metropolitanos para enfrentamento, por meio das políticas públicas, dos problemas ditos comuns entre os municípios que as integram:

- Possibilidade 1: os municípios que integram regiões metropolitanas não se articulariam nem verticalmente (com o Governo Estadual e com o Governo Federal) e nem horizontalmente, isto é, entre eles próprios.

- Possibilidade 2: os municípios que integram regiões metropolitanas instituiriam mecanismos de cooperação intergovernamental no sentido vertical (União - estados - municípios) e/ou (estados - municípios) e/ou (União municípios); 
- Possibilidade 3: os municípios que integram regiões metropolitanas instituiriam - além dos mecanismos de cooperação vertical - mecanismos de cooperação horizontal.

Quanto à possibilidade 1, no caso brasileiro, ela é praticamente inexistente, dada, dentre inúmeros fatores, a incapacidade dos municípios efetivarem suas autonomias fiscais comprometendo as outras duas autonomias: política e administrativa. Já se sabe do alto grau de dependência dos municípios brasileiros, mesmo daqueles que integram regiões metropolitanas com peso econômico significativo, em relação aos repasses de recursos estaduais e federais para manutenção das atividades e serviços que lhes competem. Desse modo, praticamente nenhum município pode dispensar a cooperação dos governos estaduais e Federal, sendo obrigados a ensejar ao menos uma articulação para implementação de suas políticas públicas urbanas que demandam vultosos recursos financeiros e investimentos para saneamento, habitação, transporte, saúde, educação etc.

Nesse sentido, é a possibilidade 2 que se efetiva mais comumente entre os municípios brasileiros, inclusos aqueles municípios que integram regiões metropolitanas.

Já a possibilidade 3 seria aquela que se almeja do ponto de vista das solidariedades institucionais baseadas nas solidariedades orgânicas e, portanto, nas articulações horizontais que conformam o lugar. Em outras palavras, além das articulações verticais entre os entes da federação, seriam as articulações horizontais entre os municípios que conformam a RM que permitiriam o enfrentamento e a resolução dos problemas ditos metropolitanos, a partir de uma ação conjunta e integrada sobre uma mesma política pública.

A falta ou a precariedade dessas articulações horizontais responderiam pelo aprofundamento dos problemas metropolitanos que não estão circunscritos pelos limites político-administrativos que separam os municípios e, portanto, não se restringem a estes, se não ao conjunto de municípios que compõem a metrópole. As linhas de transporte público, os deslocamentos pendulares casa-trabalho, o saneamento, abastecimento de água, instalação de equipamentos de uso coletivo, oferta de serviços públicos etc. não podem depender dos limites jurisdicionais dos municípios, pois a vida de relações da metrópole e as demandas por esses serviços e equipamentos extrapolam tais limites. 
É nesse sentido que emerge o problema da fragmentação territorial tendo em vista que quando os municípios cooperam verticalmente, eles o fazem de modo isolado, individual. Daí resulta a distribuição desigual de recursos ou mesmo o enfrentamento parcial de um determinado problema existente na região metropolitana.

\section{Fatores de constrangimento às articulações federativas horizontais}

Buscamos, na literatura, argumentos que explicitassem as razões que justificariam as dificuldades para 0 empreendimento de articulações federativas horizontais entre os municípios que integram regiões metropolitanas. A partir dos mais variados argumentos, identificamos ao menos cinco fatores que apontariam para a falta ou constrangimento a tais articulações, isto é, para um uso mais solidário - sobretudo do ponto de vista institucional e para execução de políticas públicas - dos territórios metropolitanos:

\section{Concentração de poder político e econômico no município-sede da RM:}

Para Davidovich (2015, p. 22), o peso político e econômico exercido pelo município-sede da RM (geralmente a capital estadual ou o município mais importante) fragilizaria a articulação horizontal entre os demais municípios metropolitanos (ibid., p 223). L. Ribeiro (2015, p. 23) corrobora com este argumento quando afirma que "o hiperpoder dos municípios capitais" não seria "utilizado para gerar uma dinâmica cooperativa, mas, ao contrário, para suportar e legitimar um padrão fragmentado e segregado de gestão dos problemas urbanos [...]".

\section{Critérios equivocados para delimitação de $R M$}

Segundo Davidovich (2015, p. 223), "a extensão demasiada de periferias, com a inclusão de municípios de baixa densidade econômica e demográfica, responderia por falsa imagem de coesão social e de integração socioespacial, sugerida pela região metropolitana".

Branco et al. (2013) corroboram com esse argumento quando, ao atualizarem os critérios responsáveis pela instituição de regiões metropolitanas ainda na década de 1970 no Brasil, perceberam que alguns municípios que atualmente ainda 
integram essas RM não deveriam, de fato, serem elevados ao status de metrópole nem à época e nem hoje - se levados em consideração a densidade populacional e o grau de integração com o município-sede.

\section{Competição entre os entes da federação e conflitos internos à RM}

Costa (2013, p. 231) afirma que os conflitos políticos, político-partidários, as disputas entre prefeitos das maiores cidades que integram a RM e governadores consistiriam em um obstáculo às cooperações intermunicipais, mediante uma "intimidação dos governos estaduais em amplificarem esses conflitos" se decidido pela busca de pactos políticos e territoriais. Adere-se, desse modo, ao isolacionismo e às cooperações intergovernamentais verticais em que cada município buscaria sozinho suas articulações com o governo estadual e/ou Federal para atendimento de suas demandas e enfrentamento de seus problemas.

Por sua vez, Castro (2006, p. 37-40) chama atenção para a indefinição e falta de clareza conceitual quanto às competências concorrentes entre os entes federados, dispostas na Constituição Federal de 1988, aumentando as tensões entre os níveis de governo em torno das atribuições e papeis a serem assumidos pelos municípios, sobretudo em um contexto marcado, na década de 1990, pela "crise fiscal e redefinição do papel do Estado em tempos de globalização" (CASTRO, 2006, p. 37-40). Destacamos que esse último problema retorna nos dias atuais.

De um ponto de vista mais técnico, mas que desembocaria em conflitos políticos e jurídicos, há também a obrigatoriedade de adequação dos Planos Diretores Municipais (PDM) ao Plano de Desenvolvimento Urbano Integrado (PDUI), em particular ao planejamento, parcelamento, uso e ocupação do solo. Essa obrigatoriedade interferiria diretamente nas competências constitucionalmente definidas e geraria controvérsias para a gestão da RM ${ }^{4}$ (MOREIRA; GUIMARÃES, 2015, p. 1.259, apud CASTRO, 2017, p. 146).

\section{4. "Ideologia" do municipalismo}

Autores apontam a chamada ideologia do municipalismo - uma das marcas indeléveis da Constituição Federal de 1988 - como uma das responsáveis pela

\footnotetext{
${ }^{4}$ Costa $(2013$, p. 231) chama atenção para o fato de que, com a Constituição Federal de 1988, a gestão metropolitana foi delegada aos estados, porém, numa Federação em que os municípios passariam a ser protagonistas na gestão de seus territórios, sem que a União fornecesse qualquer orientação ou regras para a gestão metropolitana no sentido de dirimir os impasses e conflitos entre os governos estaduais e os governos municipais que agiriam sobre o território metropolitano.
} 
dificuldade em se tecer articulações e cooperações entre os municípios que integram regiões metropolitanas.

A referida Constituição ao elevar o status do município a ente federado, o grau de descentralização e autonomia foram levados a novos patamares (CASTRO, 2006, p. 43), ao tempo em que as regiões metropolitanas se enfraqueceram institucionalmente como "resultado, em parte, da pressão dos municipalistas que pretendiam evitar um arranjo governamental que pudesse colocar em risco as autonomias locais" (ABRUCIO et al., 2013a, p. 92-93).

Clementino (2016, p. 7), por exemplo, fala da "desconfiança, por parte dos municípios, em relação a uma possível perda de autonomia", caso se efetivasse um governo metropolitano ou mesmo um arranjo institucional horizontal.

É preciso lembrar que a promulgação da Constituição Federal de 1988 ocorreu em um contexto de "aversão a qualquer estrutura e ou modelo institucional herdado do período militar" (ABRUCIO et al., 2010), sinônimo de poder autoritário que precisaria ser desmontado em prol do municipalismo e da suposta descentralização do poder.

Esse processo induziu o ente municipal como unidade territorial privilegiada para se exercer o planejamento territorial contribuindo para os constrangimentos às articulações federativas horizontais (CASTRO, 2006, p. 51-52). Nesse sentido, os municípios passaram a desempenhar um papel de desagregador ao impor constrangimentos à "prática regional de planejamento e integração de políticas públicas", cabendo destacar, ainda, "a competitividade inter-citadina" como resultado da exacerbação das autonomias subnacionais (ibid., p. 43).

5. Falta de instrumentos para financiamento e investimento em políticas públicas metropolitanas

Por fim, um quinto e último fator que consistiria em obstáculo às articulações federativas horizontais teria a ver com a falta de instrumentos exclusivos para financiamento e investimento em políticas públicas metropolitanas, ou seja, a falta de fundos metropolitanos ou - no caso da existência desses fundos - a falta de legislações que destinem obrigatoriamente recursos dos orçamentos estaduais e municipais para esses fundos compartilhados entre os municípios da RM.

Motta e Miranda (2013), ao retomarem entrevistas realizadas com técnicos e funcionários de carreira da Empresa Paulista de Planejamento Metropolitano 
(Emplasa), destacam o apontamento dos técnicos referente aos obstáculos para efetivação e implementação de projetos e planos metropolitanos mediante a ausência de um orçamento regionalizado, já que, segundo os entrevistados, não basta planejar se "não houver o compromisso de destinação de recursos, pois a efetividade da ação metropolitana ocorre, notadamente, mediante investimentos" (ibid., p. 220).

Esses seriam alguns fatores e argumentos que exporiam as dificuldades para as articulações federativas horizontais em torno do planejamento e gestão metropolitanos.

No entanto, vale destacar que, atualmente, buscando enfrentar os obstáculos e constrangimentos às articulações federativas horizontais em contextos metropolitanos, o Brasil conta com instrumentos que permitem articulações horizontais entre os municípios que integram essas regiões, em que destacamos: 1) os Consórcios de Direito Privado; 2) os Consórcio de Direito Público e; 3) os "acordos consorciais" ou pactos intermunicipais.

Para Abrucio et al. (2013b, p. 158) dois momentos/movimentos foram importantes para a difusão territorial do consórcio público como um instrumento de cooperação e articulação intermunicipal, sobretudo em regiões metropolitanas: 1) a disseminação da experiência do Consórcio Intermunicipal do Grande $A B C$ e; 2) a criação da figura normativa do consórcio de direito público instituída pela Lei Federal no 11.107, de 2005.

No entanto, tais experiências, apesar de serem importantes, ainda se apresentam pontualmente no território nacional e sem capacidade, ao menos até então, de instituírem articulações e integrações permanentes em torno das políticas públicas metropolitanas, isto é, ações com duração e extensão no tempo-espaço.

\section{Considerações Finais}

A partir dessas considerações, argumentamos que com a existência de instituições metropolitanas que de fato abrigassem as demandas emergentes do lugar e que fossem conformadas a partir da própria região metropolitana, isto é, que emergissem de baixo para cima e não de cima para baixo, é que permitir-se-ia pensar em uma saída para a resolução das demandas conflitantes entre interesses sociais e econômicos internos à metrópole e interesses exclusivamente econômicos (geralmente do mercado global) externos à metrópole e que, no caso destes últimos, a fragilizaria politicamente e a esfacelaria do ponto de vista social e territorial. 
Outro fator que dificultaria a delimitação das regiões metropolitanas teria a ver com a própria morfologia espacial assumida pela metrópole e caracterizada pela dialética concentração-dispersão do espaço construído, como já argumentado anteriormente. Até onde iriam os limites do urbano ou da cidade em uma região entrecortada por redes e fluxos $?^{5} \mathrm{E}$ até onde seria possível delimitar uma região para instituição de um governo próprio horizontal sem acirrar os atritos e conflitos já existentes que desembocam na fragmentação da metrópole? São desafios postos para se pensar, como proposto por Santos (2010), uma federação de lugares ${ }^{6}$.

Se, por um lado, a região metropolitana resulta de um processo histórico que tem a ver com o processo de urbanização, aglomeração dos grupos humanos e das atividades de produção, circulação e consumo - orientados pelo próprio Estado e pelo chamado mercado global - e que criaram esse complexo objeto técnico que é a metrópole, por outro lado, precisam ser revistas as formas pelas quais o Estado incorpora a metrópole como objeto da ação racional dirigida a determinados fins.

Essa revisão deve passar pelas atuais configurações territoriais que levem em conta duas coisas: 1) a existência da metrópole como fato, admitindo uma dada configuração territorial; 2) a existência do sistema federativo que implique outra configuração territorial.

É preciso de algum modo fazer coincidirem essas duas configurações territoriais na busca de um sistema de engenharia federativo mais condizente com às demandas dos lugares e com às dinâmicas territoriais preexistentes, sobretudo, ligadas às demandas sociais e à vida de relações dos mais pobres.

É fundamental considerar o papel e o peso desempenhado pelas fronteiras internas - no caso dos municípios que integram as RM - e pelos demais limites político-administrativos instituídos para fins de regionalização, pois é preciso considerar o fato de que o território uma vez normatizado e organizado por um dado sistema político, se torna um condicionador da ação e apresenta, por meio das fronteiras e demais limites, as possibilidades e/ou constrangimentos para realização de um dado projeto político de sociedade.

\footnotetext{
${ }^{5}$ Cataia (2011, p. 118) contesta a ideia do território como um compartimento político fechado, "pois ao mapa dos compartimentos se justapõe o mapa das redes". Essa afirmação é um tanto mais válida para o fato e fenômeno metropolitanos.

${ }^{6}$ Santos (2010, p. 95) propõe uma federação de lugares se referindo à "reconstrução da federação brasileira a partir da célula local, feita de forma que o território nacional venha a conhecer uma compartimentação que não seja também uma fragmentação. Desse modo, a federação seria refeita de baixo para cima, ao contrário da tendência a que agora está sendo arrastada pela subordinação aos processos de globalização".
} 
Tudo isso tem a ver com o peso exercido pela história e pela geografia, isto é, pelo território tornado norma e cujas cristalizações do passado materializadas no espaço não nos permite deixar escapar o papel ativo exercido pelo território (BERNARDES, et al., 2000) quando nos debruçamos sobre os limites e as possibilidades de articulações federativas horizontais, isto é, sobre a possibilidade da instituição de uma verdadeira federação de lugares, como propunha Milton Santos (2010).

\section{REFERÊNCIAS}

ABRUCIO, F. L.; SANO, H. In GARCIA, L. de O.; OLIVEIRA, N. P. de; ANTERO, S. A. (Orgs.). Associativismo Intergovernamental: experiências brasileiras. Fundação Instituto para o Fortalecimento das Capacidades Institucionais (IFCI); Agência Espanhola de Cooperação Internacional para o Desenvolvimento (AECID); Ministério do Planejamento, Orçamento e Gestão (MPOG). Editora IABS, Brasília-DF, 2013a.

ABRUCIO, F. L; FRANZESE, C.; SANO, H. Trajetória recente da cooperação e coordenação do federalismo brasileiro: avanços e desafios. In CARDOSO Jr., J. C.; BERCOVICI, G.

(Orgs.). República, democracia e desenvolvimento: contribuições ao Estado brasileiro contemporâneo. Brasília: Ipea, 2013b. p. 129-163.

ABRUCIO, F. L.; FRANZESE, C. Federalismo e políticas públicas: o impacto das relações intergovernamentais no Brasil. In ARAÚJO, M.; BEIRA, L. (Orgs.). Tópicos da Economia Paulista para Gestores Públicos. São Paulo: Fundap, 2007, v. 1, p. 13-31.

ABRUCIO, F. L.; SANO, H.; SYDOW, C. T. Radiografia do associativismo territorial brasileiro: tendências, desafios e impactos sobre as regiões metropolitanas. In KLINK, J. (Org.). Governança das Metrópoles? Conceitos, experiências e perspectivas. São Paulo: Annablume, 2010. p. 21-48.

BERNARDES, A., et al. O papel ativo da Geografia: um manifesto. In XII Encontro Nacional de Geógrafos, Florianópolis, julho de 2000.

BRANCO, M. L. G. C.; PEREIRA, R. H. M.; NADALIN, V. G. Rediscutindo a delimitação das regiões metropolitanas no Brasil: um exercício a partir dos critérios da década de 1970. In

FURTADO, B. A.; KRAUSE, C.; FRANÇA, K. C. B. de. Território metropolitano, políticas municipais: por soluções conjuntas de problemas urbanos no âmbito metropolitano.

Brasília: IPEA, 2013. p. 115-154

BRASIL. Congresso Nacional. Constituição (1988). Constituição da República Federativa do Brasil. Brasília, DF, 1988.

CASTILLO, R.; et al. Três dimensões da Solidariedade em Geografia. Autonomia políticoterritorial e tributação. In Experimental. n. 3, São Paulo, setembro, 1997. p. 69-99.

CASTRO, H. R. de. A Região Metropolitana na Federação Brasileira: estudo do caso de Londrina, Paraná. Dissertação (Mestrado), Programa de Pós-Graduação em Ciência Política, Universidade Federal do Rio de Janeiro, Rio de Janeiro, 2006.

. Coerção e coesão territorial na gestão metropolitana contemporânea. Tese

(doutorado). Pontifícia Universidade Católica de Campinas, Centro de Ciências Exatas, Ambientais e de Tecnologias, Pós-Graduação em Urbanismo. Campinas: PUC-Campinas, 2017.

CATAIA, M. Território Nacional e Fronteiras Internas: a fragmentação do território brasileiro. Tese (Doutorado). Faculdade de Filosofia, Letras e Ciências Humanas, Departamento de Geografia, Universidade de São Paulo, 2001.

. Federalismo brasileiro. As relações intergovernamentais analisadas a partir das transferências voluntárias (União/Município). In Revista Geográfica de América Central. Número Especial EGAL, Costa Rica, 2011. p. 1-16. 
CLEMENTINO, M. do L. M. Regiões metropolitanas no Brasil: visões do presente e do futuro. In XIV Coloquio Internacional de Geocrítica, Barcelona, 2016.

COSTA, M. A. Quarenta anos de regiões metropolitanas no Brasil: um breve balanço exploratório. In COSTA, M. A.; TSUKUMO, I. T. L. (Orgs.). 40 anos de regiões

metropolitanas no Brasil. Brasília: Ipea, 2013. p. 323-338

DAVIDOVICH, F. A volta da metrópole no Brasil: referências para a gestão territorial. In RIBEIRO, L. C. de Q. (Org.). Metrópoles: entre a coesão e a fragmentação, a cooperação e o conflito. 2 ed. Rio de Janeiro: Letra Capital: Observatório das Metrópoles, 2015, p. 197-230.

DE MATTOS, C. A. Redes, nodos y ciudades: transformación de la metrópoli latinoamericana. In VII Seminario Internacional de la Red Iberoamericana de Ivestigaciones sobre Globalización y Territorio (RII), Cuba, 2002. p. 1-34

Modernización capitalista y transformación metropolitana em América Latina: cinco tendências constitutivas. In LEMOS, A. I. G. de; ARROYO, M.; SILVEIRA, M. L. CLACSO - Consejo Latinoamericano de Ciencias Sociales, San Pablo, 2006. p. 41-73. DI MÉO, G. Introdução ao debate sobre a metropolização: uma chave de interpretação para compreender a organização contemporânea dos espaços geográficos. In Confins -Revista franco-brasileira de geografia, vol, 4, n. 4, 2008.

DURKHEIM, É. Da divisão do trabalho social. 2 ed. São Paulo: Martins Fontes, 1999. LENCIONI, S. Urbanização difusa e a constituição de megarregiões: o caso de São Paulo Rio de Janeiro. In e-metropolis, № 22, ano 6, 2015, p. 6-15.

MOTTA, D. M. da; MIRANDA, Z. A. I. de. Governança metropolitana na Região Metropolitana de São Paulo. In COSTA, M. A.; TSUKUMO, I. T. L. (Orgs.). 40 anos de regiões metropolitanas no Brasil. Brasília: Ipea, 2013. p. 205-230.

RIBEIRO, A. C. T. O fato metropolitano - enigma e poder. In: Por uma Sociologia do presente: ação, técnica e espaço. Rio de Janeiro: Letra Capital, vol. 3, [2013a (2007)]. O fato metropolitano: espaço e sociedade. In: Por uma Sociologia do presente: ação, técnica e espaço. Rio de Janeiro: Letra Capita, vol. 3, 2013b.

RIBEIRO, L. C. de Q. Entre a coesão e a fragmentação, a cooperação e o conflito. In RIBEIRO, L. C. de Q. (Org.). Metrópoles: entre a coesão e a fragmentação, a cooperação e o conflito. 2 ed. Rio de Janeiro: Letra Capital: Observatório das Metrópoles, 2015, p. 17-40. SABOIA, M. R. Notas sobre as regiões metropolitanas. In Brasília, a. 35, n. 138, 1998, p. 231-236.

SANTOS, M. O Espaço Dividido: os dois circuitos da economia urbana dos países subdesenvolvidos. Traducao Myrna T. Rego Viana. 2. ed. São Paulo: Edusp, 2004 [1979]. A urbanização brasileira. 5 ed. São Paulo: Edusp, 2005 [1993].

A Natureza do Espaço: técnica e tempo, razão e emoção. 4 ed. São Paulo: Edusp. 2008 [1996].

Metrópole Corporativa e Fragmentada: o caso de São Paulo. 2 ed. São Paulo:

Edusp, 2009 [1990].

Por uma outra globalização: do pensamento único à consciência universal. 19. ed. Rio de Janeiro: Record, 2010.

Edusp, 2012 [1994].

Por uma economia política da cidade: o caso de São Paulo. 2 ed. São Paulo:

SASSEN, S. Toward new urban formats. In HALL, P.; SARRAZIN, T.; SASSEN, S. et al. Cities in Schlossplatiz, Berlin: Hertie School of Governance GmbH, 2008.

SOJA, E. Para além de postmetropolis. In Revista UFMG, no 20, p. 137-167, 2013. 


\section{NOTAS DE AUTOR}

Carlos Eduardo Nobre -Concepção, coleta de dados, análise de dados, elaboração do manuscrito, revisão da versão final do trabalho

\section{FINANCIAMENTO}

Não se aplica.

\section{CONSENTIMENTO DE USO DE IMAGEM}

Não se aplica.

\section{APROVAÇÃO DE COMITÊ DE ÉTICA EM PESQUISA}

Não se aplica.

\section{CONFLITO DE INTERESSES}

Não se aplica.

\section{LICENÇA DE USO}

Este artigo está licenciado sob a Licença Creative Commons CC-BY. Com essa licença você pode compartilhar, adaptar, criar para qualquer fim, desde que atribua a autoria da obra.

\section{HISTÓRICO}

Recebido em: 16-02-2019

Aprovado em: 10-09-2019 